\title{
A whole genome SNP genotyping by DNA microarray and candidate gene association study for kidney stone disease
}

Nanyawan Rungroj ${ }^{1,2}$, Choochai Nettuwakul ${ }^{1}$, Nirinya Sudtachat ${ }^{1,3}$, Oranud Praditsap ${ }^{4}$, Nunghathai Sawasdee , Suchai Sritippayawan ${ }^{5}$, Duangporn Chuawattana ${ }^{5}$ and Pa-thai Yenchitsomanus ${ }^{1 *}$

\begin{abstract}
Background: Kidney stone disease (KSD) is a complex disorder with unknown etiology in majority of the patients. Genetic and environmental factors may cause the disease. In the present study, we used DNA microarray to genotype single nucleotide polymorphisms (SNP) and performed candidate gene association analysis to determine genetic variations associated with the disease.

Methods: A whole genome SNP genotyping by DNA microarray was initially conducted in 101 patients and 105 control subjects. A set of 104 candidate genes reported to be involved in KSD, gathered from public databases and candidate gene association study databases, were evaluated for their variations associated with KSD.

Results: Altogether 82 SNPs distributed within 22 candidate gene regions showed significant differences in SNP allele frequencies between the patient and control groups $(P<0.05)$. Of these, 4 genes including BGLAP, AHSG, CD44, and HAO1, encoding osteocalcin, fetuin-A, CD44-molecule and glycolate oxidase 1, respectively, were further assessed for their associations with the disease because they carried high proportion of SNPs with statistical differences of allele frequencies between the patient and control groups within the gene. The total of 26 SNPs showed significant differences of allele frequencies between the patient and control groups and haplotypes associated with disease risk were identified. The SNP rs759330 located 144 bp downstream of BGLAP where it is a predicted microRNA binding site at $3^{\prime} U T R$ of PAQR6 - a gene encoding progestin and adipoQ receptor family member $\mathrm{VI}$, was genotyped in 216 patients and 216 control subjects and found to have significant differences in its genotype and allele frequencies ( $P=0.0007, \mathrm{OR} 2.02$ and $P=0.0001, \mathrm{OR} 2.02$, respectively).
\end{abstract}

Conclusions: Our results suggest that these candidate genes are associated with KSD and PAQR6 comes into our view as the most potent candidate since associated SNP rs759330 is located in the miRNA binding site and may affect mRNA expression level.

Keywords: Kidney stone disease, Nephrolithiasis, Genetic association study, Single nucleotide polymorphisms, Candidate gene

\footnotetext{
* Correspondence: ptyench@gmail.com

'Division of Molecular Medicine, Department of Research and Development, Faculty of Medicine Siriraj Hospital, Mahidol University, Bangkok 10700,

Thailand

Full list of author information is available at the end of the article
} 


\section{Background}

Kidney stone disease (KSD) is a major clinical problem causing medical care expenses and public health burden worldwide. The etiology of kidney stone is heterogeneous, ranging from monogenic defect to complex interaction between genetic and environmental factors [1]. KSD is endemic in the northeastern (NE) population of Thailand. The most recent investigation from our group demonstrated that it is indeed prevalent in this population and the risk of having the disease is higher among members of affected families, compared to that of the normal control population, indicating an involvement of a genetic factor, although its actual etiology is still unidentified [2].

The technology to identify genetic polymorphisms, especially single nucleotide polymorphism (SNP), is available as a tool for studying genes associated with many diseases $[3,4]$. Genetic contribution to kidney stone formation has been well recognized, and a number of studies have reported genetic variations of several human genes, including osteopontin (OPN) [5,6], calcitonin receptor (CTR) [7], vitamin D receptor (VDR) [8], urokinase [9], interleukin (IL-1 $\beta$ and IL-Ra) [10,11], E-cadherin [12], androgen-oestrogen receptors (AR and ER) [13], vascular endothelial receptor growth factor (VEGF) [14], and calcium-sensing receptor (CaSR) [15], which associated with KSD with a predominantly hypercalciuria and calcium oxalate kidney stones. However, these reported genes had little effect on clarifying the contribution to KSD and a frequent genetic abnormality causing the disease has not been elucidated. Two previous genomewide association studies (GWAS) examined the whole genomic DNA with many thousands of SNPs and reported genes that were associated with KSD. Sequence variations in claudin 14 (CLDN14) gene associated with KSD in the population from Iceland and the Netherlands have been reported [16]. Subsequently, the same research group described that uromodulin (UMOD) variant affected risk of chronic kidney disease by providing protection against KSD [17].

To investigate genetic variations associated with KSD in NE Thai population, our group has previously reported the result of case-control association study in 112 subjects each of patient and control groups. We genotyped 67 SNPs distributed within 8 candidate genes, namely TFF1, S100A8, S100A9, S100A12, AMBP, SPP1, UMOD, and F2, that encode stone inhibitor proteins, including trefoil factor 1, calgranulin (A, B, and C), bikunin, osteopontin, TammHorsfall protein, and prothrombin, respectively. We found that minor allele and homozygous genotype frequencies of 8 from 10 analyzed SNPs distributed within the $F 2$ gene were significantly higher in the control group than those in the patient group. In addition, two F2 haplotypes were found to be dually associated with kidney stone (one with decreased risk and the other with increased risk) in the female group, indicating that $F 2$ variations influence the risk of KSD in the NE Thai female patients [18]. We further examined and reported the association between a specific $F 2$ variation (T165M) and KSD in our recent work [19].

The genes that have been reported for their association with KSD in other populations may serve as candidate genes for initial screening in the population of interest that is affected by this disease. In this study, we initially carried out a whole genome SNP genotyping by DNA microarray. The genetic variations associated with KSD in the NE Thai population were then determined by candidate gene association study using data of the reported candidate genes involved in KSD. The result showed that at least four candidate genes were associated with KSD in the NE Thai population studied.

\section{Methods}

\section{Subjects}

The study was approved by Siriraj Institutional Review Board and the Ethics Committees of the Ministry of Public Health, Thailand. A written informed consent was obtained from individual subject before conducting this study. A group of 216 patients with KSD (135 females and 81 males, aged 22-80 years), recruited from Khon Kaen Regional Hospital in the northeastern part of Thailand, were studied. Of these, $64 \%$ have family history. The 216 healthy control subjects (126 females and 90 males), who were age-matched, unrelated, and had no history of KSD, were recruited from the same geographical region. More details of the patients and the healthy control subjects as well as the diagnostic procedures have been described in our previous report [19]. Genomic DNA samples of the patients and control subjects were extracted from peripheral blood samples using the standard phenol-chloroform method.

\section{Genotyping}

The genomic DNA samples from 101 patients and 105 normal control subjects were genotyped by using the Affymetrix Genome-Wide Human SNP Array 6.0 and following the manufacturer's instructions (http://www.affymetrix. $\mathrm{com} /$ support/technical/byproduct.affx?product=genomewidesnp_6). The genotyping was conducted by Vanderbilt Functional Genomics Shared Resource (Vanderbilt University, USA). Briefly, genomic DNA (500 ng) was digested with Nsp I and Sty I restriction enzymes and ligated to adaptors. A single generic primer that recognizes the adaptor sequence was used to amplify adaptor-ligated DNA fragments. PCR amplification products for each restriction enzyme digest were combined and purified using polystyrene beads. The amplified products were then fragmented, labeled, and hybridized to a SNP Array 6.0. Genotyping Console $^{\text {tux }}$ Software was used for genotype calling. 


\section{Candidate gene search}

Candidate genes for KSD were searched and chosen for the study and statistical analysis from data sources presented during 1990-2011. Traditional or manual literature search was carried out using PubMed database (http://www.ncbi.nlm.nih.gov/pubmed/). Two additional resources, SNPs3D (http://snps3d.org/) [20] and HuGE Navigator (http://www.hugenavigator.org/HuGENavigator/home.do) [21], were also used to assist in screening candidate genes from published human genetic association studies using the keywords related to KSD. Candidate genes were selected according to the following criteria: encoding protein involving in KSD (i.e. ion exchange or ion channel protein), stone promoter or inhibitor proteins, proteins involving pathways of calcium, kidney acid-base homeostasis proteins, and metabolic enzymes.

\section{Determination of SNPs in candidate gene regions}

SNPs in candidate gene regions (including $1 \mathrm{~kb}$ upstream and $1 \mathrm{~kb}$ downstream of transcript position) from the genotyping result of 101 case and 105 control subjects were determined for their association with KSD. SNPs with call rate of genotyping less than 90\% were excluded. Candidate genes that showed significant differences of SNP allele frequencies between the patient and control groups were further assessed for their involvement in the disease by analyses of their individual SNPs and haplotypes.

\section{Sequencing}

Specific primers for PCR amplification and sequencing in the regions of promoter, all exons, and exon-intron boundaries of BGLAP and AHSG genes were designed by Primer3 program (http://frodo.wi.mit.edu/primer3/) (the sequences of PCR primers are available on request). PCR amplification and sequencing were performed in 6 patients and 6 control subjects. The PCR was performed using the Immolase ${ }^{\mathrm{Tu}}$ DNA polymerase (Bioline, USA) with 0.5 pmol each of forward and reverse primers, $1 \mathrm{x}$ Immolase buffer, $1.5-3 \mathrm{mM} \mathrm{MgCl} 2$ and $100 \mathrm{ng}$ of genomic DNA. The cycling conditions were set as follows: one cycle at $94^{\circ} \mathrm{C}$ for $10 \mathrm{~min}, 30$ cycles of denaturation at $94^{\circ} \mathrm{C}$ for $30 \mathrm{sec}$, annealing at $64-67^{\circ} \mathrm{C}$ for $1 \mathrm{~min}$, and extension at $72^{\circ} \mathrm{C}$ for $45 \mathrm{sec}$.

The PCR products were purified for direct sequencing by using ExoSAP-IT ${ }^{\circledR}$ (Affymetrix, USA). All sequencing PCR reactions were conducted under BigDye ${ }^{\text {TM }}$ Terminator Cycling conditions using 3730XL DNA analyzer (Applied Biosystems ${ }^{\mathrm{mm}}$, USA) by Macrogen Inc (South Korea). The sequences were evaluated and compared with the reference nucleotide sequences of BGLAP (NC_000001.10) and AHSG (NC_000003.11) by multiple sequence alignment using ClustalW2 program (http:// www.ebi.ac.uk/Tools/clustalw2/index.html).

\section{SNP genotyping by a high-resolution melting method}

Three SNPs located in BGLAP gene region and the adjacent PAQR6 gene (a novel SNP in exon 3, rs759330, and rs7513351) and two SNPs (rs4917 and rs4918) of AHSG were genotyped by high-resolution melting (HRM) method. PCR and HRM analysis for these SNPs were prepared in 384-well plate and performed on a LightCycler 480 II machine (Roche Diagnotics, Germany). All PCR reactions were optimized by performing reactions in $20 \mu \mathrm{L}$ volumes containing $125 \mathrm{ng}$ genomic DNA in $1 \mathrm{x}$ Immolase buffer, $0.5 \mu \mathrm{M}$ of each primer, $0.2 \mathrm{mM}$ dNTP, $1.5 \mathrm{mM} \mathrm{MgCl}_{2}, 0.25$ unit of DNA polymerase (Immolase, Bioline, USA), and 1x Resolight dye (Roche Diagnostics, Germany). The PCR condition included an initial denaturation at $95^{\circ} \mathrm{C}$ for $10 \mathrm{~min}$, followed by 35 cycles of $95^{\circ} \mathrm{C}$ for $20 \mathrm{sec}, 60-68^{\circ} \mathrm{C}$ for $20 \mathrm{sec}$, and $72^{\circ} \mathrm{C}$ for $20 \mathrm{sec}$. Before the HRM step, the product was heated to $95^{\circ} \mathrm{C}$ for $30 \mathrm{sec}$ and then cooled to $40^{\circ} \mathrm{C}$. Melting curves were obtained by increasing the temperature from $65-97^{\circ} \mathrm{C}$ with 25 acquisitions of continuous florescence detection. The melting curves were normalized, temperature-shifted and converted to difference plots by Gene Scan software. The sequences of PCR primers are available on request.

In some cases in which the melting curves and difference plots of amplicons from the samples with homozygous wild-type and variants were unable to be differentiated, they were further analyzed by spiking the DNA sample carrying homozygous wild-type into the tested samples to allow the detection of heteroduplex DNA molecules generated from the homozygous variant samples $[22,23]$.

\section{Statistical analysis}

According to the SNP genotyping data of microarray, significant difference SNPs $(P<0.05)$ between 101 patients and 105 normal control subjects were examined by GenABEL package with no adjustment for binary traits; the test is equivalent to the Armitage test [24]. Statistical tests for Hardy-Weinberg equilibrium (HWE) and for association between SNP frequencies and disease phenotype were performed by 3 web-based programs including DeFinetti (http://ihg.gsf.de/cgi-bin/hw/hwal.pl, SNPStats (http://bioinfo.iconcologia.net/snpstats/start.htm), and Haploview (http://www.broad.mit.edu/mpg/haploview/). $P$-values were calculated using a chi-square test or Fisher's exact test. $P<0.05$ was considered statistically significant in the calculation to compare their differences. The Haploview software package was used to estimate the pair-wise linkage disequilibrium (LD) and haplotype block structure using the confidence intervals algorithm. 
Bonferroni's correction for multiple testing was applied by multiplying $P$-value by the number of observed haplotypes.

\section{Results}

\section{Candidate genes for kidney stone disease}

To identify and collect candidate genes involved in KSD, all published articles or abstracts in the genetic studies of KSD and its genetic association studies were searched both from the PubMed database and by using SNPs3D and HuGE Navigator. Altogether 104 candidate genes (97 genes on autosome and 7 genes on chromosome X) were gathered: 48 genes from manual literature search from PubMed, 64 genes from SNPs3D, and 49 genes from Phenopedia of HuGE Navigator (Additional file 1: Table S1).

\section{Potential candidate genes with significant SNPs}

A total of 1,559 SNPs located within 104 candidate gene regions were taken from the genotyping results analyzed by using Affymetrix Genome-Wide Human SNP Array
6.0 of the patient and normal control groups and were primarily evaluated for their variations associated with KSD. Several criteria were considered for further selection, i.e., number of analyzed SNP on microarray, number of significant SNP, ratio of significant SNP and SNP on microarray of each gene, gene expression data, and protein function information. The result demonstrated that 82 SNPs distributed within 22 candidate gene regions, 20 genes on autosome and 2 genes on chromosome $\mathrm{X}$, showed significant differences of SNP allele frequencies between the patient and control groups (uncorrected $P<0.05$ ) (Table 1). After Bonferroni's correction for 1,559 comparisons, the new statistical significance cut off is $P=0.000032$ and none of SNP can pass this requirement. Of these, 5 candidate genes, including BGLAP, SLC2A9, EGFR, CD44, and HAO1, had at least one SNP that showed highly significant differences of allele frequencies between the patient and control groups at $P<0.005$. By taking the number of SNP with significant $P$-value within the gene into consideration, 4 candidate genes including BGLAP, AHSG, CD44,

Table 1 Candidate genes and SNPs associated with KSD

\begin{tabular}{|c|c|c|c|c|c|}
\hline \multirow[t]{2}{*}{ Gene } & \multicolumn{3}{|c|}{ Number of SNP in gene region } & \multirow{2}{*}{$\begin{array}{c}\text { SNP with } \\
\text { the least } \\
P \text {-value }\end{array}$} & \multirow[t]{2}{*}{$P$-value ${ }^{c}$} \\
\hline & SNP on microarray & SNP with $P<0.05$ & SNP with $P<0.005$ & & \\
\hline S100A12 & 1 & 1 & 0 & rs4772 & 0.04258 \\
\hline$B G L A P$ & 1 & 1 & 1 & rs759330 & 0.00070 \\
\hline HSPG2 & 30 & 3 & 0 & rs16826053 & 0.01248 \\
\hline ILIR1 & 19 & 1 & 0 & rs871657 & 0.04641 \\
\hline AHSG & 3 & 2 & 0 & rs2070635 & 0.02556 \\
\hline CLDN16 & 8 & 1 & 0 & rs17504970 & 0.00651 \\
\hline SLC2A9 & 122 & 21 & 1 & rs939134 & 0.00428 \\
\hline SLC26A2 & 6 & 1 & 0 & rs245081 & 0.03632 \\
\hline EDN1 & 10 & 2 & 0 & rs2070699 & 0.02020 \\
\hline EGFR & 92 & 2 & 2 & rs7801956 & 0.00958 \\
\hline$C A L C R$ & 54 & 1 & 0 & rs13232226 & 0.03644 \\
\hline SLC26A5 & 33 & 1 & 0 & rs17142677 & 0.04889 \\
\hline CAV1 & 19 & 2 & 0 & rs6867 & 0.03657 \\
\hline CD44 & 52 & 12 & 1 & rs353647 & 0.00298 \\
\hline$F 2$ & 6 & 1 & 0 & rs2070852 & 0.01117 \\
\hline$V D R$ & 39 & 4 & 0 & rs2254210 & 0.01815 \\
\hline RASGRP1 & 21 & 7 & 0 & rs7177101 & 0.00701 \\
\hline ANXA2 & 23 & 4 & 0 & rs7183894 & 0.03945 \\
\hline $\mathrm{CDH} 1$ & 33 & 1 & 0 & rs12444784 & 0.04469 \\
\hline HAOI & 35 & 11 & 4 & rs6118004 & 0.00179 \\
\hline$A R$ & 21 & 1 & 0 & rs5031002 & 0.02756 \\
\hline HPRT1 & 3 & 2 & 0 & rs6634993 & 0.04254 \\
\hline
\end{tabular}

${ }^{a}$ SNP was significantly different between patients and control subjects only in male group.

${ }^{b}$ SNP was significantly different between patients and control subjects only in female group.

'Uncorrected $P$-value. 
and HAO1 which encode osteocalcin, fetuin-A, CD44 molecule, and glycolate oxidase 1, respectively, were selected to be further assessed for their involvement in KSD by analyses of individual SNPs and haplotypes because they carried high proportion of SNPs with statistical differences of allele frequencies between the patient and control groups within the gene (ClinVar database accession number: SCV00147950-66). The detail of each candidate gene is described below.

\section{BGLAP}

Only one SNP, rs759330, located 144 bp downstream of BGLAP gene was identified from the result of DNA microarray. This SNP was in HWE and showed significant differences of allele frequency between the patient and control groups with $P=0.0009$. The analysis also revealed that genotype frequency significantly differed $(P=0.0027)$ with the model of dominant inheritance that gave the least value of Akaike's Information Criterion (AIC). The patient group had significantly higher proportions of the combination of heterozygous genotypes of major/minor alleles $(\mathrm{T} / \mathrm{C})$ and homozygous genotypes of minor alleles $(\mathrm{C} / \mathrm{C})$ than that of the control group, indicating that $\mathrm{C}$ allele was susceptible to KSD with odds ratio (OR) 2.44 (Table 2). However, this association was not statistically significant after correction for 1,559 comparisons. To confirm this association, we conducted the genotyping of SNP rs759330 in 101 patients and 105 controls and the additional DNA samples of 115 patients and 111 controls to make up the total numbers of 216 each of patient and control groups by the HRM method. The differences of allele and genotype frequencies between the patient and control groups were statistically significant at $P=0.0001$ and 0.0007 (corrected $P=$ 0.0005 and 0.0035 ), respectively (Table 2 ).

To examine whether there were other SNPs linked to SNP rs759330, the whole BGLAP gene including its promoter region, all 4 exons and introns were amplified (as a single fragment) and sequenced in 6 patients and 6 normal control subjects. An exoinc non-synonymous
SNP rs182775321 was detected. However, the results of genotyping of this SNP carried out by the HRM method in 112 of each of patient and control groups showed no significant differences of genotype and allele frequencies between the patient and control groups $(P=0.780$ and 0.778). In addition, the results of genotyping of rs7513351 - a SNP positioned 664 bp from rs759330 which is located on PAQR6 gene nearby the BGLAP carried out by the HRM method in 112 of each of patient and control groups showed no significant differences of genotype and allele frequencies between the patient and control groups $(P=0.960$ and 0.0 .831$)$ (data not shown).

The Haploview software package was used to estimate the pair-wise linkage disequilibrium (LD) and haplotype block structure from the genotyping data of 3 SNPs (rs182775321, rs759330, and rs7513351) from 101 patients and 105 control subjects. The result showed that these 3 SNPs were not in LD block.

\section{AHSG}

Three SNPs (rs2248690, rs2070634, and rs2070635) located in AHSG gene region were analyzed. All analyzed SNPs were in HWE. SNP allele frequencies showed significant differences between the patient and control groups for 2 SNPs located in intron 4, rs2070634 and rs2070635 $(P=0.0329$ and 0.0256$)$. Analysis of individual SNPs in patient and control groups using the web-based SNPStats program revealed that genotype frequencies of rs2070634 and rs2070635 significantly differed (Table 3). The model of inheritance considered by the least value of AIC was found to be recessive for both SNPs with significant differences. The patient group had significantly higher proportions of homozygous genotypes of minor alleles than that of the control group for rs2070634 and rs2070635 ( $P=0.023$ and 0.017$)$, indicating that homozygous genotypes of minor alleles were susceptible to kidney stone with ORs 2.49 and 2.52, respectively.

One LD block spanning $6 \mathrm{~kb}$ containing all 3 SNPs was defined from the genotyping data of 101 patients

Table 2 Genotype and allele frequencies of SNP rs759330 in BGLAP gene

\begin{tabular}{|c|c|c|c|c|c|c|c|c|c|}
\hline \multirow[t]{2}{*}{ Genotype } & \multicolumn{2}{|c|}{ Genotype frequency (\%) } & \multirow[t]{2}{*}{ OR $(95 \% \mathrm{Cl})$} & \multirow{2}{*}{$\begin{array}{c}P \text {-value } \\
\text { (Corrected) }\end{array}$} & \multirow[t]{2}{*}{ Allele } & \multicolumn{2}{|c|}{ Allele frequency (\%) } & \multirow[t]{2}{*}{ OR $(95 \% \mathrm{Cl})$} & \multirow{2}{*}{$\begin{array}{c}P \text {-value } \\
\text { (Corrected) }\end{array}$} \\
\hline & Control & Patient & & & & Control & Patient & & \\
\hline SNP array & $(n=105)$ & $(n=101)$ & & & & $(n=105)$ & $(n=101)$ & & \\
\hline$T / T$ & 75.2 & 55.5 & 1.00 & $0.0027(4.2093)$ & $\mathrm{T}$ & 87.1 & 74.3 & 1.00 & $\mathbf{0 . 0 0 0 9}(1.4031)$ \\
\hline $\mathrm{T} / \mathrm{C}, \mathrm{C} / \mathrm{C}$ & 24.8 & 44.5 & $2.44(1.35-4.41)$ & & C & 12.9 & 25.7 & $2.35(1.41-3.92)$ & \\
\hline HRM & $(n=216)$ & $(n=216)$ & & & & $(n=216)$ & $(n=216)$ & & \\
\hline$T / T$ & 75.0 & 59.7 & 1.00 & $0.0007(0.0035)$ & $\mathrm{T}$ & 87.0 & 76.9 & 1.00 & $0.0001(0.0005)$ \\
\hline $\mathrm{T} / \mathrm{C}, \mathrm{C} / \mathrm{C}$ & 25.0 & 40.3 & $2.02(1.34-3.05)$ & & C & 13.0 & 23.1 & $2.02(1.41-2.90)$ & \\
\hline
\end{tabular}

$\mathrm{OR}$, odds ratio; $\mathrm{Cl}$, confidence interval.

Corrected $P$-values are adjusted for multiple comparisons (1,559 tests for SNP array and 5 tests for HRM method). Statistical significance cut off values are $P=0.00032$ and $P=0.01$ for the analyses by SNP array and HRM, respectively.

Significant $P$-values are indicated in bold. 
Table 3 Genotype and allele frequencies of SNPs in AHSG gene observed in 105 control subjects and 101 patients

\begin{tabular}{|c|c|c|c|c|c|c|c|c|c|c|}
\hline \multirow[t]{2}{*}{ SNP ID } & \multirow[t]{2}{*}{ Genotype } & \multicolumn{2}{|c|}{ Genotype frequency (\%) } & \multirow[t]{2}{*}{ OR $(95 \% \mathrm{Cl})$} & \multirow[t]{2}{*}{$P$-value* } & \multirow[t]{2}{*}{ Allele } & \multicolumn{2}{|c|}{ Allele frequency (\%) } & \multirow[t]{2}{*}{ OR $(95 \% \mathrm{Cl})$} & \multirow[t]{2}{*}{$P$-value* } \\
\hline & & Control & Patient & & & & Control & Patient & & \\
\hline \multirow[t]{2}{*}{ rs2070634 } & $\mathrm{G} / \mathrm{G}, \mathrm{G} / \mathrm{T}$ & 90.5 & 79.2 & 1.00 & 0.023 & G & 65.7 & 55.4 & 1.00 & 0.0329 \\
\hline & $\mathrm{T} / \mathrm{T}$ & 9.5 & 20.8 & $2.49(1.11-5.60)$ & & $\mathrm{T}$ & 34.3 & 44.6 & $1.54(1.03-2.29)$ & \\
\hline \multirow[t]{2}{*}{ rs2070635 } & $\mathrm{C} / \mathrm{C}, \mathrm{C} / \mathrm{T}$ & 89.5 & 77.2 & 1.00 & 0.017 & C & 65.2 & 54.5 & 1.00 & 0.0256 \\
\hline & $\mathrm{T} / \mathrm{T}$ & 10.5 & 22.8 & $2.52(1.60-5.49)$ & & $\mathrm{T}$ & 34.8 & 45.5 & $1.57(1.06-2.33)$ & \\
\hline
\end{tabular}

$\mathrm{OR}$, odds ratio; $\mathrm{Cl}$, confidence interval.

*Uncorrected $P$-value.

Significant $P$-values are indicated in bold.

and 105 control subjects with 3 observed haplotypes (Additional file 2: Figure S1, Additional file 3: Table S2). The most common haplotype, AGC (frequency $=0.600$ ), was significantly more frequent in the control group (frequency $=0.652$ ) than in the patient group (frequency $=0.545)$ with a $P$-value of $0.0256($ OR $0.64,95 \%$
CI 0.43 - 0.951), indicating its association with decreased disease risk. In contrast, ATT haplotype was more represented in the patient group (frequency $=0.285$ ) than in the control group (frequency $=0.186$ ) with a $P$-value of 0.0170 (OR 1.743, 95\% CI $1.098-2.769$ ), indicating its association with increased disease risk. However, after

Table 4 Genotype and allele frequencies of SNPs in CD44 gene observed in 105 control subjects and 101 patients

\begin{tabular}{|c|c|c|c|c|c|c|c|c|c|c|}
\hline \multirow[t]{2}{*}{ SNP ID } & \multirow[t]{2}{*}{ Genotype } & \multicolumn{2}{|c|}{ Genotype frequency (\%) } & \multirow[t]{2}{*}{ OR $(95 \% \mathrm{Cl})$} & \multirow[t]{2}{*}{$P$-value* } & \multirow[t]{2}{*}{ Allele } & \multicolumn{2}{|c|}{ Allele frequency (\%) } & \multirow[t]{2}{*}{ OR $(95 \% \mathrm{Cl})$} & \multirow[t]{2}{*}{$P$-value* } \\
\hline & & Control & Patient & & & & Control & Patient & & \\
\hline \multirow[t]{2}{*}{ rs353623 } & $\mathrm{C} / \mathrm{C}$ & 69.2 & 83.2 & 1.00 & 0.018 & C & 81.2 & 90.6 & 1.00 & 0.0066 \\
\hline & $\mathrm{C} / \mathrm{T}, \mathrm{T} / \mathrm{T}$ & 30.8 & 16.8 & $0.46(0.23-0.89)$ & & $\mathrm{T}$ & 18.8 & 9.4 & $0.45(0.25-0.81)$ & \\
\hline \multirow[t]{2}{*}{ rs353618 } & $\mathrm{A} / \mathrm{A}$ & 69.5 & 83.2 & 1.00 & 0.021 & A & 81.4 & 90.6 & 1.00 & 0.0075 \\
\hline & $\mathrm{A} / \mathrm{G}, \mathrm{G} / \mathrm{G}$ & 30.5 & 16.8 & $0.46(0.24-0.90)$ & & G & 18.6 & 9.4 & $0.45(0.25-0.82)$ & \\
\hline \multirow[t]{2}{*}{ rs353612 } & $\mathrm{C} / \mathrm{C}$ & 86.7 & 95 & 1.00 & 0.034 & C & 92.9 & 97.5 & 1.00 & 0.0275 \\
\hline & $\mathrm{C} / \mathrm{T}, \mathrm{T} / \mathrm{T}$ & 13.3 & 5 & $0.34(0.12-0.98)$ & & $\mathrm{T}$ & 7.1 & 2.5 & $0.33(0.12-0.92)$ & \\
\hline \multirow[t]{2}{*}{ rs353637 } & $\mathrm{T} / \mathrm{T}$ & 87.1 & 96 & 1.00 & 0.022 & $\mathrm{~T}$ & 93.6 & 98 & 1.00 & 0.0286 \\
\hline & $\mathrm{T} / \mathrm{A}$ & 12.9 & 4 & $0.29(0.09-0.91)$ & & A & 6.4 & 2 & $0.30(0.10-0.94)$ & \\
\hline \multirow[t]{2}{*}{ rs353630 } & $\mathrm{G} / \mathrm{G}$ & 86.7 & 95 & 1.00 & 0.034 & G & 93.3 & 97.5 & 1.00 & 0.0426 \\
\hline & $\mathrm{G} / \mathrm{A}$ & 13.3 & 5 & $0.34(0.12-0.98)$ & & A & 6.7 & 2.5 & $0.35(0.13-1.00)$ & \\
\hline \multirow[t]{2}{*}{ rs353647 } & $\mathrm{G} / \mathrm{G}$ & 50.5 & 70.3 & 1.00 & 0.0035 & G & 71.4 & 83.7 & 1.00 & 0.0030 \\
\hline & $\mathrm{G} / \mathrm{C}, \mathrm{C} / \mathrm{C}$ & 49.5 & 29.7 & $0.43(0.24-0.76)$ & & C & 28.6 & 16.3 & $0.49(0.30-0.79)$ & \\
\hline \multirow[t]{2}{*}{ rs3794110 } & $\mathrm{C} / \mathrm{C}$ & 74 & 87 & 1.00 & 0.019 & C & 87 & 93 & 1.00 & 0.0446 \\
\hline & $\mathrm{C} / \mathrm{T}, \mathrm{T} / \mathrm{T}$ & 26 & 13 & $0.43(0.21-0.88)$ & & $\mathrm{T}$ & 13 & 7 & $0.50(0.26-0.99)$ & \\
\hline \multirow[t]{2}{*}{ rs3794109 } & $\mathrm{A} / \mathrm{A}$ & 74.3 & 87.1 & 1.00 & 0.019 & A & 87.1 & 93.1 & 1.00 & 0.0446 \\
\hline & $\mathrm{A} / \mathrm{G}, \mathrm{G} / \mathrm{G}$ & 25.7 & 12.9 & $0.43(0.21-0.88)$ & & G & 12.9 & 6.9 & $0.50(0.26-0.99)$ & \\
\hline \multirow[t]{2}{*}{ rs112762 } & $\mathrm{C} / \mathrm{C}$ & 42.9 & 58.4 & 1.00 & 0.025 & C & 65.2 & 76.7 & 1.00 & 0.0103 \\
\hline & $\mathrm{C} / \mathrm{T}, \mathrm{T} / \mathrm{T}$ & 57.1 & 41.6 & $0.53(0.31-0.93)$ & & $\mathrm{T}$ & 34.8 & 23.3 & $0.57(0.37-0.88)$ & \\
\hline \multirow[t]{2}{*}{ rs10488809 } & $\mathrm{T} / \mathrm{T}$ & 75.2 & 87.1 & 1.00 & 0.028 & $\mathrm{~T}$ & 87.6 & 93.1 & 1.00 & 0.0618 \\
\hline & $\mathrm{T} / \mathrm{A}, \mathrm{A} / \mathrm{A}$ & 24.8 & 12.9 & $0.45(0.22-0.93)$ & & A & 12.4 & 6.9 & $0.53(0.27-1.04)$ & \\
\hline \multirow[t]{2}{*}{ rs3794105 } & $\mathrm{G} / \mathrm{G}$ & 86.7 & 95 & 1.00 & 0.034 & G & 93.3 & 97.5 & 1.00 & 0.0426 \\
\hline & $\mathrm{G} / \mathrm{A}$ & 13.3 & 5 & $0.34(0.12-0.98)$ & & A & 6.7 & 2.5 & $0.35(0.13-1.00)$ & \\
\hline \multirow[t]{2}{*}{ rs7110737 } & $\mathrm{T} / \mathrm{T}$ & 36.2 & 43.6 & 1.00 & 0.28 & $\mathrm{~T}$ & 58.1 & 67.8 & 1.00 & 0.0411 \\
\hline & $\mathrm{T} / \mathrm{A}, \mathrm{A} / \mathrm{A}$ & 63.8 & 56.4 & $0.73(0.42-1.29)$ & & A & 41.9 & 32.2 & $0.66(0.44-0.98)$ & \\
\hline \multirow[t]{2}{*}{ rs7116432 } & $\mathrm{C} / \mathrm{C}$ & 43 & 55.2 & 1.00 & 0.087 & C & 65 & 74.5 & 1.00 & 0.0413 \\
\hline & $\mathrm{C} / \mathrm{T}, \mathrm{T} / \mathrm{T}$ & 57 & 44.8 & $0.61(0.35-1.08)$ & & $\mathrm{T}$ & 35 & 25.5 & $0.64(0.41-0.98)$ & \\
\hline
\end{tabular}

OR, odds ratio; $\mathrm{Cl}$, confidence interval.

*Uncorrected $P$-value.

Significant $P$-values are indicated in bold. 
Bonferroni's correction for 3 comparisons, the differences were not statistically significant $(P=0.0768$ and 0.0510$)$.

All of the 7 exons, including exon-intron boundary, and promoter region of AHSG gene were amplified and sequenced in 6 patients and 6 control subjects. A total of 3 exonic SNPs were detected, a synonymous SNP (rs4831) in exon 1 and two non-synonymous SNPs (rs4917 and rs4918) in exons 6 and 7, respectively. Genotyping of 2 non- synonymous SNPs, rs4917 and rs4918, was carried out by HRM method in 112 each of patient and control groups. However, no significant differences of allele and genotype frequencies between the patient and control groups of both SNPs were found $(P=0.203$ and 0.242$)$ (data not shown).

\section{CD44}

A total of 52 SNPs located in $C D 44$ gene region were analyzed. Three monomorphic SNPs (rs1467558, rs10488811, and rs16927100) were observed and were excluded from further statistical analysis. Allele frequencies of 12 SNPs showed significant differences $(P<0.05)$ between the patient and control groups (Table 4). Analysis of individual SNPs in the patient and control groups by using the SNPStats program revealed 11 SNPs with significant differences of genotype frequencies. In the dominant model of inheritance for these SNPs, the control group had significantly higher proportions of the combination of heterozygous genotypes of major/minor alleles and homozygous genotypes of minor alleles than that of the patient group, indicating that minor alleles were protective to KSD with ORs between 0.29 and 0.53 (Table 4).

Seven LD blocks containing 8, 3, 2, 2, 6, 3 and 4 SNPs were defined from the genotyping data of 101 patients and 105 control subjects with 4, 3, 3, 2, 5, 4 and 3 observed haplotypes for blocks 1-7 (Additional file 4: Figure S2 and Additional file 5: Table S3). The GTGTTGGC, AAC, and CCATTC haplotypes of the blocks 1,2 and 5 were significantly more frequent in controls than patients with $P=0.0075,0.0414$, and 0.0082 , respectively, indicating its association with decreased disease risk. In contrast, the GCACTC and ACC haplotypes of the blocks 5 and 6 were significantly more frequent in the patients than the controls with $P=$ 0.0103 and 0.0114 , respectively, indicating the association with increased disease risk. After Bonferroni's correction for multiple testing by multiplying $P$-value by the number of observed haplotypes in each block, the differences remained statistically significant only for the haplotypes GTGTTGGC, CCATTC and ACC of blocks 1,5 , and $6(P=0.03,0.041$, and 0.0456 , respectively).

\section{HAO1}

All 35 SNPs on microarray located in HAO1 gene region were analyzed for HWE and genotype and allele frequencies of the patient and control groups. Initially, 3 SNPs (rs1983560, rs2423331, and rs7271299) which were found to have low call rate of genotyping (less than $90 \%$ ) in either the patient or control groups were disqualified. Two monomorphic SNPs (rs8124232 and rs16994134) were observed in both groups and were excluded from further statistical analysis. Allele frequencies of 11 SNPs showed significant differences $(P<0.05)$ between the patient and control groups (Table 5). Analysis of individual SNPs in the patient and control groups using the SNPStats program revealed significant differences of genotype frequencies of 10 SNPs. The model of inheritance considered by the least value of AIC was found to be dominant for the SNPs with significant differences. The patient group had significantly higher proportions of the alleles than that of the control group, indicating that associated alleles increase the risk of KSD (Table 5).

Three LD blocks spanning 17, 20, and $7 \mathrm{~kb}$ containing 5,12 , and 2 SNPs were defined from the genotyping data of 101 patients and 105 control subjects with 4, 5, and 2 observed haplotypes for blocks 1, 2, and 3, respectively (Additional file 6: Figure S3 and Additional file 7: Table S4). The GGGAC haplotype of the first block was significantly more frequent in the patients than in the controls with $P=0.0193$ (OR $1.615,95 \%$ CI 1.08- 2.414), indicating its association with increased disease risk. In contrast, the CAACGCTCAAAG and AT haplotypes of the second and the third blocks were significantly more frequent in the controls than in the patients with $P=$ 0.0045 (OR 0.479, 95\% CI 0.286-0.801) and 0.0399 (OR 0.598, 95\% CI 0.365- 0.979), indicating the association with decreased disease risk. After Bonferroni's correction for multiple testing by multiplying $P$-value by the number of observed haplotypes in each block, the differences remained statistically significant only for the haplotype of block $2(P=0.0225)$.

\section{Discussion}

Over the last decade, a number of studies have been conducted to identify genetic factors contributing to KSD. Candidate gene approach is an important tool for this endeavour. In the present candidate gene association study, initially conducted in $101 \mathrm{NE}$ Thai patients and 105 control subjects, we identified 82 different SNPs in 22 genes that showed suggestive associations with KSD from the initial analysis of 104 reported candidate genes. Four genes, including BGLAP, AHSG, CD44, and HAO1, were selected as candidate genes of KSD in NE Thai population for further analyses since they carried SNPs with highly statistical differences $(P<0.005)$ of allele frequencies between the patient and control groups and high proportion of significant SNPs within the gene. 
Table 5 Genotype and allele frequencies of SNPs in HAO1 gene observed in 105 control subjects and 101 patients

\begin{tabular}{|c|c|c|c|c|c|c|c|c|c|c|}
\hline \multirow[t]{2}{*}{ SNP ID } & \multirow[t]{2}{*}{ Genotype } & \multicolumn{2}{|c|}{ Genotype frequency (\%) } & \multirow[t]{2}{*}{ OR $(95 \% \mathrm{Cl})$} & \multirow[t]{2}{*}{$P$-value* } & \multirow[t]{2}{*}{ Allele } & \multicolumn{2}{|c|}{ Allele frequency (\%) } & \multirow[t]{2}{*}{ OR $(95 \% \mathrm{Cl})$} & \multirow[t]{2}{*}{$P$-value* } \\
\hline & & Control & Patient & & & & Control & Patient & & \\
\hline \multirow[t]{2}{*}{ rs6055363 } & $\mathrm{A} / \mathrm{A}$ & 44.8 & 32 & 1.00 & 0.06 & A & 67.6 & 57 & 1.00 & 0.0265 \\
\hline & $\mathrm{A} / \mathrm{G}, \mathrm{G} / \mathrm{G}$ & 55.2 & 68 & $1.72(0.97-3.04)$ & & G & 32.4 & 43 & $1.57(1.05-2.36)$ & \\
\hline \multirow[t]{2}{*}{ rs2294305 } & $\mathrm{A} / \mathrm{A}$ & 43.8 & 31 & 1.00 & 0.058 & A & 66.7 & 56.5 & 1.00 & 0.0343 \\
\hline & $\mathrm{A} / \mathrm{G}, \mathrm{G} / \mathrm{G}$ & 56.2 & 69 & $1.74(0.98-3.08)$ & & G & 33.3 & 43.5 & $1.54(1.03-2.30)$ & \\
\hline \multirow[t]{2}{*}{ rs2235250 } & $\mathrm{G} / \mathrm{G}$ & 44.8 & 31.7 & 1.00 & 0.053 & G & 68.1 & 55.9 & 1.00 & 0.0110 \\
\hline & $\mathrm{G} / \mathrm{A}, \mathrm{A} / \mathrm{A}$ & 55.2 & 68.3 & $1.75(0.99-3.09)$ & & A & 31.9 & 44.1 & $1.68(1.12-2.51)$ & \\
\hline \multirow[t]{2}{*}{ rs6077285 } & $\mathrm{C} / \mathrm{C}$ & 28 & 46.9 & 1.00 & 0.0057 & C & 57.5 & 66.8 & 1.00 & 0.0555 \\
\hline & $\mathrm{C} / \mathrm{G}, \mathrm{G} / \mathrm{G}$ & 72 & 53.1 & $0.440(0.24-0.79)$ & & G & 42.5 & 33.2 & $0.67(0.45-1.01)$ & \\
\hline \multirow[t]{2}{*}{ rs2294301 } & $\mathrm{C} / \mathrm{C}$ & 34.3 & 53.5 & 1.00 & 0.0054 & C & 60 & 69.8 & 1.00 & 0.0373 \\
\hline & $\mathrm{C} / \mathrm{G}, \mathrm{G} / \mathrm{G}$ & 65.7 & 46.5 & $0.450(0.26-0.80)$ & & G & 40 & 30.2 & $0.65(0.43-0.98)$ & \\
\hline \multirow[t]{2}{*}{ rs2423326 } & $\mathrm{G} / \mathrm{G}$ & 34.3 & 54.5 & 1.00 & 0.0035 & G & 60 & 72.8 & 1.00 & 0.0061 \\
\hline & $\mathrm{G} / \mathrm{A}, \mathrm{A} / \mathrm{A}$ & 65.7 & 45.5 & $0.440(0.25-0.77)$ & & A & 40 & 27.2 & $0.56(0.37-0.85)$ & \\
\hline \multirow[t]{2}{*}{ rs6118004 } & $\mathrm{T} / \mathrm{T}$ & 33.3 & 58 & 1.00 & 0.0004 & $\mathrm{~T}$ & 60 & 74.5 & 1.00 & 0.0018 \\
\hline & $\mathrm{T} / \mathrm{C}, \mathrm{C} / \mathrm{C}$ & 66.7 & 42 & $0.360(0.21-0.64)$ & & C & 40 & 25.5 & $0.51(0.34-0.78)$ & \\
\hline \multirow[t]{2}{*}{ rs2205818 } & $\mathrm{A} / \mathrm{A}$ & 35.2 & 57.4 & 1.00 & 0.0013 & A & 61.9 & 74.3 & 1.00 & 0.0072 \\
\hline & $\mathrm{A} / \mathrm{G}, \mathrm{G} / \mathrm{G}$ & 64.8 & 42.6 & $0.40(0.23-0.71)$ & & G & 38.1 & 25.7 & $0.56(0.37-0.86)$ & \\
\hline \multirow[t]{2}{*}{ rs2142697 } & $\mathrm{T} / \mathrm{T}$ & 34 & 56.6 & 1.00 & 0.0012 & $\mathrm{~T}$ & 61.2 & 74.2 & 1.00 & 0.0050 \\
\hline & $\mathrm{T} / \mathrm{C}, \mathrm{C} / \mathrm{C}$ & 66 & 43.4 & $0.40(0.22-0.70)$ & & C & 38.8 & 25.8 & $0.55(0.36-0.83)$ & \\
\hline \multirow[t]{2}{*}{ rs6140463 } & $\mathrm{G} / \mathrm{G}$ & 35.2 & 58 & 1.00 & 0.001 & G & 61.4 & 74.5 & 1.00 & 0.0046 \\
\hline & $\mathrm{G} / \mathrm{A}, \mathrm{A} / \mathrm{A}$ & 64.8 & 42 & $0.39(0.22-0.69)$ & & A & 38.6 & 25.5 & $0.54(0.36-0.83)$ & \\
\hline \multirow[t]{2}{*}{ rs2235245 } & $\mathrm{C} / \mathrm{C}$ & 35.2 & 58.4 & 1.00 & 0.0008 & C & 61.4 & 75.2 & 1.00 & 0.0026 \\
\hline & $\mathrm{C} / \mathrm{G}, \mathrm{G} / \mathrm{G}$ & 64.8 & 41.6 & $0.39(0.22-0.68)$ & & G & 38.6 & 24.8 & $0.52(0.34-0.80)$ & \\
\hline \multirow[t]{2}{*}{ rs6086287 } & $\mathrm{A} / \mathrm{A}$ & 72.4 & 58.4 & 1.00 & 0.035 & A & 84.8 & 77.2 & 1.00 & 0.0510 \\
\hline & $\mathrm{A} / \mathrm{C}, \mathrm{C} / \mathrm{C}$ & 27.6 & 41.6 & $1.87(1.04-3.34)$ & & C & 15.2 & 22.8 & $1.64(0.99-2.70)$ & \\
\hline \multirow[t]{2}{*}{ rs2255183 } & $\mathrm{T} / \mathrm{T}$ & 71.4 & 56.4 & 1.00 & 0.025 & $\mathrm{~T}$ & 84.3 & 76.2 & 1.00 & 0.0399 \\
\hline & $\mathrm{T} / \mathrm{C}, \mathrm{C} / \mathrm{C}$ & 28.6 & 43.6 & $1.93(1.08-3.44)$ & & C & 15.7 & 23.8 & $1.67(1.02-2.74)$ & \\
\hline
\end{tabular}

$\mathrm{OR}$, odds ratio; $\mathrm{Cl}$, confidence interval.

*Uncorrected $P$-value.

Significant $P$-values are indicated in bold.

BGLAP gene encodes osteocalcin or bone gammacarboxyglutamate (gla) protein. This vitamin K-dependent protein is related to bone resorption and may change blood levels of calcium ions [25]. In mouse, osteocalcin has a similar pattern of expression and identical structural features to nephrocalcin, a calcium-binding protein partially purified from kidney that plays a role in calcium reabsorption and in prevention of nephrolithiasis [26]. Therefore, osteocalcin might associate with kidney stone disease. However, the Hind III polymorphism located at the promoter region was not correlated with calcium oxalate stone disease in Taiwanese patients [27]. In the present study, rs759330 located 144 bp downstream of BGLAP gene showed significant differences of allele frequency between the 216 patients and 216 control subjects with $P=$ 0.0001 . This result indicates the association of BGLAP and the disease; however, the functional SNP could not be identified. Only one exonic SNP, rs182775321, was detected in BGLAP by DNA sequencing but it showed no significant differences of genotype and allele frequencies between the patient and control groups. Interestingly, while we were looking for other candidate genes close to rs759330 that may be involved in the disease, we found that this SNP is located in the 3'UTR of PAQR6 gene encoding progestin and adipoQ receptor family member VI. Prediction for miRNA binding site by using MicroCosm Targets at EMBL-EBI (http://www.ebi.ac.uk/enright-srv/ microcosm/htdocs/targets/v5/) revealed that rs759330 is located at the binding site of hsa-miR-424\%. The entire sequence of predicted binding site for hsa-miR-424* at $3^{\prime}$ UTR of PAQR6 gene including the position of rs759330 is shown (Additional file 8: Figure S4).

PAQR6 has been reported to have progestin-binding characteristics [28]. The kidney was found to be the site 
of receptors for progesterone [29] and progesterone can stimulate $\mathrm{Ca}^{2+}$ reabsorption at distal part of the nephron [30]. The level of PAQR6 expression may correlate with progesterone that stimulates $\mathrm{Ca}^{2+}$ reabsorption in the kidney and it may be involved in pathogenesis of KSD. In the present study, we found that the patient group had significantly higher proportions of $\mathrm{C}$ allele of rs759330 than the control group, indicating that $\mathrm{C}$ allele was susceptible to KSD. Since rs759330 is located at binding site of hsa-miR-424*, the presence of rs759330$\mathrm{C}$ allele may decrease $P A Q R 6$ expression leading to reduction of progesterone receptors in the kidney. The reduction of progesterone molecule which associates with decreased level of $\mathrm{Ca}^{2+}$ reabsorption may increase risk of KSD. For this reason, rs759330 may affect miRNA binding resulting in mRNA expression level. The relationship between PAQR6 and KSD requires further investigation.

AHSG gene encodes fetuin-A or alpha-2-HS-glycoprotein, a circulating calcium-regulatory glycoprotein that inhibits extraosseous calcification. It has been reported that the patients with urolithiasis had lower urinary fetuin-A levels compared with that of healthy subjects [31]. In addition, two AHSG gene polymorphisms, rs4917 and rs4918, were evaluated in 103 Turkish patients with calcium oxalate nephrolithiasis and 73 healthy subjects. The results revealed that rs 4918 was associated with higher risk for renal calcium oxalate stone formation [32]. In our study, 3 SNPs on microarray were initially analyzed and the allele and genotype frequencies of rs2070634 and rs2070635 were significantly different between the patient and control groups (Table 3). Two AHSG haplotypes were slightly associated with kidney stone risk, haplotype AGC with decreased disease risk and haplotype ATT with increased disease risk. However, the associations of both haplotypes were not statistically significant after correction. Two nonsynonymous SNPs, rs4917 and rs4918, were also genotyped in 112 each of patient and control groups but no significant differences of allele and genotype frequencies between the patient and control groups were observed. This result is different from that of the previous study, showing that rs4918 was associated with KSD in Turkish patients [31]. Our result demonstrated that rs4918 was not associated with kidney stone formation in the population studied $(P=0.66$, OR $0.78,95 \%$ CI $0.51-1.18)$. The different result may be attributable to genetic diversity among these two populations and also the small numbers of patients and control subjects included in the present study.

CD44 gene encodes CD44 molecule. This transmembrane protein is a receptor for hyaluronic acid (HA) and can also interact with osteopontin (OPN), a major component in the urinary stone matrix that inhibits nucleation, growth, and aggregation of $\mathrm{CaOx}$ crystals and also reduces binding of crystals to renal epithelial cells in vitro [33-36]. In a study in rat, the expression of HA, OPN, and CD44 by injured/regenerating tubular cells seems to play a role in crystal retention in the kidney [37]. Thus, CD44 may be a candidate gene of KSD. In this association study, genotype or allele frequencies of 13 SNPs in the CD44 gene were significantly different between the patient and control groups (Table 4). Haplotypes associated with decreased and increased kidney stone risk were also identified but they were observed in a different haplotype block with different frequency (Additional file 5: Table S3). This study indicates the potency of $C D 44$ gene for KSD in the population studied. However, the variants causing the disease should be further investigated.

HAO1 gene encodes glycolate oxidase 1. Human glycolate oxidase catalyzes flavin mononucleotide -dependent oxidation of glycolate to glyoxylate, and of glyoxylate to oxalate. The presence of glycolate oxidase 1 in liver and kidney peroxisomes and its ability to oxidize glyoxylate to oxalate, a key metabolite in the kidney stone formation, is of particular importance for individuals with primary hyperoxaluria type I, as a consequence of their inability to convert glyoxylate to glycine in the peroxisome [38-40]. In our study, we found 13 different SNPs, having either genotype or allele frequencies with significant differences between the patient and control groups (Table 5). Haplotypes associated with decreased and increased disease risks were also observed (Additional file 7: Table S4), indicating the potency of $H A O 1$ gene for KSD in the population studied although the variants associated with the disease should be further investigated.

Although a genome-wide association study (GWAS) was conducted in 101 patients and 105 control subjects in the beginning of this study, a potential variation could not be identified. Initially, 57 SNPs distributed on the genome were found to have statistical significance after correction by qualified 684,142 SNPs on microarray. Of these, 28 SNPs were located in the gene regions but the ratios of significant SNPs over non-significant SNPs within the same genes were low. In addition, only 6 SNPs were predicted to have functional impacts as examined by SNP Function Prediction (FuncPred, The National Institute of Environmental Health Sciences (NIEHS) http://snpinfo. niehs.nih.gov/snpinfo/snpfunc.htm) and when one SNP each in a gene of interest was selected to for validation, it was found to be false positive results. The unsuccessful analysis by GWAS in this study may be attributable to the small sample size leading to low statistical power (power 0.44 as calculated by Quanto, http://biostats.usc.edu/ software). This led us to change the analysis method to be candidate gene association study. When an alternative approach by candidate gene association study of 104 reported candidate genes were taken, a number of potential 
variants were identified and a SNP rs759330 in PAQR6 was validated in 216 each of patient and control groups by HRM method, the statistical power was increased to be 0.87 . However, a larger sample size is required to validate the relationship of other candidate genes. Although a low-powered sample size is a limitation of this study, the association study based on the reported candidate genes has made it possible to identify the potential candidate genes and the associated SNPs for KSD in the studied population.

\section{Conclusions}

In conclusion, our study suggests that BGLAP together with PAQR6, AHSG, HAO1, and CD44 are potential candidates associated with KSD in NE Thai patients. Replication studies with a larger sample size are necessary to validate these associations. Of these, PAQR6 comes into our view as the most potent candidate since the associated SNP rs759330 is located in the miRNA binding, which may affect mRNA expression level.

\section{Additional files}

Additional file 1: Table S1. Candidate genes for kidney stone disease searched from PubMed, SNPs3D, and HuGE Navigator.

Additional file 2: Figure S1. Linkage disequilibrium (LD) plots showing D' and LD block of 3 genotyped SNPS in AHSG gene from 101 patients and 105 controls determined by the Haploview program.

Additional file 3: Table S2. Association between haplotypes consisting of 3 SNPS of AHSG gene and kidney stone risk.

Additional file 4: Figure S2. Linkage disequilibrium (LD) plots showing D' and LD block of 49 genotyped SNPs in CD44 gene from 101 patients and 105 controls determined by the Haploview program.

Additional file 5: Table S3. Association between haplotypes consisting of 49 SNPs of CD44 gene and kidney stone risk.

Additional file 6: Figure S3. Linkage disequilibrium (LD) plots showing D' and LD block of 30 genotyped SNPs in HAO1 gene from 101 patients and 105 controls determined by the Haploview program.

Additional file 7: Table S4. Association between haplotypes consisting of 30 SNPs of HAO1 gene and kidney stone risk.

Additional file 8: Figure S4. MicroRNA hsa-miR-424* binding site at $3^{\prime}$ UTR of PAQR6 gene and the position of rs759330.

\section{Abbreviations}

KSD: Kidney stone disease; SNP: Single nucleotide polymorphism; HRM: Highresolution melting; AIC: Akaike's Information Criterion; OR: Odds ratio.

\section{Competing interests}

The authors do not have any conflicts of interest, financial or otherwise, to declare.

\section{Authors' contributions}

NR and PY designed the study and wrote the article; NR, CN, NSu and OP carried out the molecular genetic studies and analyzed the data; NSa, SS, DC and PY collected the samples and participated in clinical data collection. All authors read and approved the final manuscript.

\section{Acknowledgements}

We thank Drs. Sombat Borvornpadungkitti, Chagkrapan Predanon, and Wattanachai Susaengrat (Khon Kaen Regional Hospital, Khon Kaen, Thailand) for the recruitment of patients, clinical data collection, and logistics in field studies. This work was financially supported by grants from Mahidol University and Thailand Research Fund (TRF). NR and PY are supported by Chalermphrakiat Grant, Faculty of Medicine Siriraj Hospital, Mahidol University. OP is supported by TRF-RGJ Ph.D. Scholarship. PY is a TRF-Senior Research Scholar.

\section{Author details}

'Division of Molecular Medicine, Department of Research and Development, Faculty of Medicine Siriraj Hospital, Mahidol University, Bangkok 10700, Thailand. ${ }^{2}$ Division of Molecular Genetics, Department of Research and Development, Faculty of Medicine Siriraj Hospital, Mahidol University, Bangkok, Thailand. ${ }^{3}$ Medical Biotechnology Unit, National Center for Genetic Engineering and Biotechnology (BIOTEC), National Science and Technology Development Agency (NSTDA), Bangkok, Thailand. ${ }^{4}$ Department of Immunology and Immunology Graduate Program, Faculty of Medicine Siriraj Hospital, Mahidol University, Bangkok, Thailand. ${ }^{5}$ Division of Nephrology, Department of Medicine, Faculty of Medicine Siriraj Hospital, Mahidol University, Bangkok, Thailand.

Received: 24 September 2013 Accepted: 28 April 2014 Published: 2 May 2014

\section{References}

1. Coe FL, Evan A, Worcester E: Kidney stone disease. J Clin Invest 2005, 115(10):2598-2608

2. Sritippayawan S, Borvornpadungkitti S, Paemanee A, Predanon C, Susaengrat W, Chuawattana D, Sawasdee N, Nakjang S, Pongtepaditep S, Nettuwakul C, Rungroj N, Vasuvattakul S, Malasit P, Yenchitsomanus PT: Evidence suggesting a genetic contribution to kidney stone in northeastern Thai population. Urol Res 2009, 37(3):141-146.

3. Manolio TA, Collins FS: The HapMap and genome-wide association studies in diagnosis and therapy. Annu Rev Med 2009, 60:443-456.

4. Nakamura Y: DNA variations in human and medical genetics: 25 years of my experience. J Hum Genet 2009, 54(1):1-8.

5. Gao B, Yasui T, Itoh Y, Li Z, Okada A, Tozawa K, Hayashi Y, Kohri K: Association of osteopontin gene haplotypes with nephrolithiasis. Kidney Int 2007, 72(5):592-598.

6. Liu CC, Huang SP, Tsai LY, Wu WJ, Juo SH, Chou YH, Huang CH, Wu MT: The impact of osteopontin promoter polymorphisms on the risk of calcium urolithiasis. Clin Chim Acta 2010, 411(9-10):739-743.

7. Chen WC, Wu HC, Lu HF, Tsai FJ: Calcitonin receptor gene polymorphism: a possible genetic marker for patients with calcium oxalate stones. Eur Urol 2001, 39(6):716-719.

8. Chen WC, Chen HY, Lu HF, Hsu CD, Tsai FJ: Association of the vitamin D receptor gene start codon Fok I polymorphism with calcium oxalate stone disease. BJU Int 2001, 87(3):168-171.

9. Tsai FJ, Lin CC, Lu HF, Chen HY, Chen WC: Urokinase gene 3'-UTR T/C polymorphism is associated with urolithiasis. Urology 2002, 59(3):458-461.

10. Chen WC, Wu HC, Chen HY, Wu MC, Hsu CD, Tsai FJ: Interleukin-1 $\beta$ gene and receptor antagonist gene polymorphisms in patients with calcium oxalate stones. Urol Res 2001, 29(5):321-324.

11. Mittal RD, Bid HK, Manchanda PK, Kapoor R: Association of interleukin-1 $\beta$ gene and receptor antagonist polymorphisms with calcium oxalate urolithiasis. J Endourol 2007, 21(12):1565-1570.

12. Tsai FJ, Wu HC, Chen HY, Lu HF, Hsu CD, Chen WC: Association of E-cadherin gene $3^{\prime}$-UTR C/T polymorphism with calcium oxalate stone disease. Urol Int 2003, 70(4):278-281.

13. Chen WC, Wu HC, Lin WC, Wu MC, Hsu CD, Tsai FJ: The association of androgen- and oestrogen-receptor gene polymorphisms with urolithiasis in men. BJU Int 2001, 88(4):432-436.

14. Chen WC, Chen HY, Wu HC, Wu MC, Hsu CD, Tsai FJ: Vascular endothelial growth factor gene polymorphism is associated with calcium oxalate stone disease. Urol Res 2003, 31(3):218-222.

15. Vezzoli G, Terranegra A, Arcidiacono T, Biasion R, Coviello D, Syren ML, Paloschi V, Giannini S, Mignogna G, Rubinacci A, Ferraretto A, Cusi D, Bianchi G, Soldati L: R990G polymorphism of calcium-sensing receptor does produce a gain-of-function and predispose to primary hypercalciuria. Kidney Int 2007, 71(11):1155-1162.

16. Thorleifsson G, Holm H, Edvardsson V, Walters GB, Styrkarsdottir U, Gudbjartsson DF, Sulem P, Halldorsson BV, de Vegt F, d'Ancona FC, den Heijer M, Franzson L, Christiansen C, Alexandersen P, Rafnar T, Kristjansson K, 
Sigurdsson G, Kiemeney LA, Bodvarsson M, Indridason OS, Palsson R, Kong A, Thorsteinsdottir U, Stefansson K: Sequence variants in the CLDN14 gene associate with kidney stones and bone mineral density. Nat Genet 2009, 41(8):926-930

17. Gudbjartsson DF, Holm H, Indridason OS, Thorleifsson G, Edvardsson V, Sulem P, de Vegt F, d'Ancona FC, den Heijer M, Wetzels JF, Franzson L, Rafnar T, Kristjansson K, Bjornsdottir US, Eyjolfsson GI, Kiemeney LA, Kong A, Palsson R, Thorsteinsdottir U, Stefansson K: Association of variants at UMOD with chronic kidney disease and kidney stones-role of age and comorbid diseases. PLoS Genet 2010, 6(7):e1001039.

18. Rungroj N, Sritippayawan S, Thongnoppakhun W, Paemanee A, Sawasdee N, Nettuwakul C, Sudtachat N, Ungsupravate D, Praihirunkit P, Chuawattana D, Akkarapatumwong V, Borvornpadungkitti S, Susaengrat W, Vasuvattakul S, Malasit P, Yenchitsomanus PT: Prothrombin haplotype associated with kidney stone disease in Northeastern Thai patients. Urology 2011, 77(1):249. e17-23.

19. Rungroj N, Sudtachat N, Nettuwakul C, Sawasdee N, Praditsap O, Jungtrakoon P, Sritippayawan S, Chuawattana D, Borvornpadungkitti S, Predanon C, Susaengrat W, Yenchitsomanus PT: Association between human prothrombin variant (T165M) and kidney stone disease. PLoS One 2012, 7(9):e45533.

20. Yue P, Melamud E, Moult J: SNPs3D: candidate gene and SNP selection for association studies. BMC Bioinforma 2006, 7:166.

21. Yu W, Gwinn M, Clyne M, Yesupriya A, Khoury MA: Navigator for human genome epidemiology. Nat Genet 2008, 40(2):124-125.

22. Liew M, Pryor R, Palais R, Meadows C, Erali M, Lyon E, Wittwer C: Genotyping of single-nucleotide polymorphisms by high-resolution melting of small amplicons. Clin Chem 2004, 50(7):1156-1164.

23. Nettuwakul C, Sawasdee N, PT Y s: Rapid detection of solute carrier family 4, member 1 (SLC4A1) mutations and polymorphisms by high-resolution melting analysis. Clin Biochem 2010, 43(4-5):497-504.

24. Aulchenko YS, Ripke S, Isaacs A, van Duijn CM: GenABEL: an R library for genome-wide association analysis. Bioinformatics 2007, 23(10):1294-1296.

25. Strohmaier WL, Schlee-Giehl K, Bichler KH: Osteocalcin response to calcium-restricted diet: a helpful tool for the workup of hypercalciuria. Eur Urol 1996, 30(1):103-107.

26. Desbois C, Hogue DA, Karsenty G: The mouse osteocalcin gene cluster contains three genes with two separate spatial and temporal patterns of expression. J Biol Chem 1994, 269(2):1183-1190.

27. Chen WC, Chen HY, Wu JY, Chen YT, Tsai FJ: Osteocalcin gene Hind II polymorphism is not correlated with calcium oxalate stone disease. Urol Res 2001, 29(2):98-101.

28. Tang YT, Hu T, Arterburn M, Boyle B, Bright JM, Emtage PC, Funk WD: PAQR proteins: a novel membrane receptor family defined by an ancient 7-transmembrane pass motif. J Mol Evol 2005, 61(3):372-380.

29. Shughrue PJ, Stumpf WE, Sar M: The distribution of progesterone receptor in the 20 day old foetal mouse: an autoradiographic study with 125I-progestin. Endocrinology 1988, 123(5):2382-2389.

30. Brunette MG, Leclerc M: Renal action of progesterone: effect on calcium reabsorption. Mol Cell Endocrinol 2002, 194(1-2):183-190.

31. Stejskal D, Karpisek M, Vrtal R, Student V, Solichova P, Fiala R, Stejskal P: Urine fetuin-A values in relation to the presence of urolithiasis. BJU Int 2008, 101(9):1151-1154

32. Aksoy H, Aksoy Y, Ozturk N, Aydin HR, Yildirim AK, Akçay F: Fetuin-A gene polymorphism in patients with calcium oxalate stone disease. Urology 2010, 75(4):928-932.

33. Aruffo A, Stamenkovic I, Melnick M, Underhill CB, Seed B: CD44 is the principal cell surface receptor for hyaluronate. Cell 1990, 61(7):1303-1313.

34. Weber GF, Ashkar S, Glimcher MJ, Cantor H: Receptor-ligand interaction between CD44 and osteopontin (Eta-1). Science 1996, 271(5248):509-512.

35. Wesson JA, Worcester EM, Wiessner JH, Mandel NS, Kleinman JG: Control of calcium oxalate crystal structure and cell adherence by urinary macromolecules. Kidney Int 1998, 53(4):952-957.

36. Xie Y, Sakatsume M, Nishi S, Narita I, Arakawa M, Gejyo F: Expression, roles, receptors, and regulation of osteopontin in the kidney. Kidney Int 2001, 60(5):1645-1657.

37. Asselman M, Verhulst A, De Broe ME, Verkoelen CF: Calcium oxalate crystal adherence to hyaluronan-, osteopontin-, and CD44-expressing injured/ regenerating tubular epithelial cells in rat kidneys. J Am Soc Nephrol 2003, 14(12):3155-3166
38. Danpure CJ: Molecular etiology of primary hyperoxaluria type 1: new directions for treatment. Am J Nephrol 2005, 25(3):303-310.

39. Jones JM, Morrell JC, Gould SJ: Identification and characterization of HAOX1, HAOX2, and HAOX3, three human peroxisomal 2-hydroxy acid oxidases. J Biol Chem 2000, 275(17):12590-12597.

40. Murray MS, Holmes RP, Lowther WT: Active site and loop 4 movements within human glycolate oxidase: implications for substrate specificity and drug design. Biochemistry 2008, 47(8):2439-2449.

doi:10.1186/1471-2350-15-50

Cite this article as: Rungroj et al: A whole genome SNP genotyping by DNA microarray and candidate gene association study for kidney stone disease. BMC Medical Genetics 2014 15:50.

\section{Submit your next manuscript to BioMed Central and take full advantage of:}

- Convenient online submission

- Thorough peer review

- No space constraints or color figure charges

- Immediate publication on acceptance

- Inclusion in PubMed, CAS, Scopus and Google Scholar

- Research which is freely available for redistribution

Submit your manuscript at www.biomedcentral.com/submit
Biomed Central 